\title{
Properties of Biobased Rigid Polyurethane Foams Reinforced with Fillers: Microspheres and Nanoclay
}

\author{
Hongyu Fan, ${ }^{1}$ Ali Tekeei, ${ }^{2}$ Galen J. Suppes, ${ }^{2}$ and Fu-Hung Hsieh ${ }^{1}$ \\ ${ }^{1}$ Department of Biological Engineering, University of Missouri-Columbia, 248 AE Building, Columbia, MO 65211, USA \\ ${ }^{2}$ Department of Chemical Engineering, University of Missouri-Columbia, W2033 Lafferre Hall, Columbia, MO 65211, USA
}

Correspondence should be addressed to Fu-Hung Hsieh, hsiehf@missouri.edu

Received 27 September 2011; Revised 15 November 2011; Accepted 29 November 2011

Academic Editor: Sadhan C. Jana

Copyright (C 2012 Hongyu Fan et al. This is an open access article distributed under the Creative Commons Attribution License, which permits unrestricted use, distribution, and reproduction in any medium, provided the original work is properly cited.

\begin{abstract}
The effect of incorporating 1-7\% microsphere and nanoclay fillers on the physical properties of polyurethane (PU) foams containing 15\% soybean oil-based polyol was investigated. Increasing filler percentage reduced the PU foam density. The compressive strength of PU foams decreased slightly when increasing the microsphere content from 1 to $3 \%$ and then increased. At $7 \%$ microsphere content, the foams displayed the same compressive strength as the control foams made from $100 \%$ petroleum polyol. For PU foams reinforced with nanoclay, their compressive strength changed little from 1 to $5 \%$, but decreased at $7 \%$ due to a lower density and weaker matrix structure. Foams containing 5 to $7 \%$ microspheres or 3 to $7 \%$ nanoclay had density-compressive strength comparable or superior to the control. Foams reinforced with fillers had more cells and smaller cell size than foams made from $15 \%$ soy-polyol but without fillers. During the foaming process, the maximal temperatures reached by PU foams were not affected by the presence of 1 to $7 \%$ of microspheres or nanoclay, but slightly lower than the control. In addition, foams with fillers displayed roughly the same thermal conductivity as soy-polyol based foams without fillers.
\end{abstract}

\section{Introduction}

Polyurethanes are very important polymers and have a surprising array of commercial applications. In recent years, polyurethane (PU) foams remain the largest demand sector, accounting for two-thirds of the total PU demand. In addition, this demand for PU foams, especially in construction and transportation, continues to strengthen across the globe. The main raw materials of PU foams are polyol and isocyanate, both are derived from petroleum [1]. However, in recent years, high energy and feedstock costs have undercut margins, forcing producers to raise price significantly for polyol and isocyanate. Also, the polyol supply is tight as demand increases greatly globally, especially in emerging regions such as China, the Middle East, and Africa [2, 3]. Increasing costs of petrochemical feedstocks and public desire for environmentally friendly green products motivate many researchers to explore sustainable and renewable biobased polyols to replace petrochemical polyols.

Soybeans are the dominant oilseed in the U.S. and account for about 90 percent of U.S. oilseed production.
Soybeans were also the first bioengineered crops to achieve commercial success and the popularity of bioengineered soybeans among USA farmers improves the soybean production attributes, such as higher yields and lower price $[4,5]$. Thus, soybean oil is promising and has great potential as the raw material of biobased polyol to replace petrochemical polyol. In fact, rigid PU foams from a mixture of petrochemical polyol and soybean oil-based polyol have been reported in recent years $[6,7]$.

Soybean oil-based polyols (SBOPs) used in making rigid PU foams in general have a hydroxyl number ranging from 150-250, lower than that of 400-500 in petrochemical polyols [8]. Derived from the triglycerides of soybean oil, SBOPs contain secondary hydroxyl groups, which are located in the middle of the triglyceride alkyl chains [9]. Upon crosslinking, a portion of these chains in the polyol is not in the polymer network and is left dangling. These pendant chains can act as a plasticizer, and thereby reduce the polymer rigidity and meanwhile increase flexibility when the foam is under loading [8]. Also, when hydroxyl groups are located in the middle of the chains, steric hindrance to cross-linking 
would occur because of the bulky aromatic isocyanate [10, 11]. Thus, rigid PU foams made from SBOPs tend to have inferior loading properties and lower compressive strength than petroleum-based PU foams.

Chang et al. [12] studied the mechanical properties of water-blown rigid polyurethane foams with addition of soy flour. In their results, both the density and compressive strength increased when increasing the soy flour content. Lin and Hsieh [13] incorporated soy protein isolate and soy fiber into water-blown flexible polyurethane foams. They found that the density of flexible foams also increased with increasing biomass materials. Banik and Sain [14] enhanced the foam loading property by incorporating cellulosic materials such as fibers, but the effect was limited due to the tendency to aggregate for cellulosic materials. Nanofibers and nanoparticles are being developed and/or discovered in recent years. Because of their extremely high surface area to volume ratio, they can influence the physical properties of the material when brought into it [15]. Widya and Macosko [16] incorporated montmorillonite-based organoclay into rigid PU foams. They reported that the addition of $1 \mathrm{wt} \%$ clay reduced cell size and increased cell number density on 300-isocyanate index foams. Both smaller cell size and dispersed nanoclay decreased the permeability of blowing agent. The compression strengths decreased with clay loading for the 250-isocyanate index foams, probably because the presence of clay interfered with the polymer formation. But there was no significant difference when compared with that of the 300-isocyanate index foams, because the reduction in compression strength caused by clay might have been offset by the decrease in cell size. Cao et al. [17] synthesized PU nanocomposite foams with modified layered silicates (organoclays). They found that the silicate layers of organoclay could be exfoliated in the PU matrix by adding hydroxyl and organotin functional groups on the clay surface. With addition of $5 \%$ organically treated clays, a significant increase in reduced compressive strength and modulus was observed. But opposite effects were observed in PU nanocomposite foams with highly cross-linked structure probably due to the interference of the $\mathrm{H}$-bond in the clay. They concluded that the overall mechanical property depended on the competition between the positive effects of clay on polymer reinforcement and foam morphology, and the negative effects on H-bond formation and network structure. Mondal and Khakhar [18] studied the properties of high-density $\left(140-160 \mathrm{~kg} / \mathrm{m}^{3}\right)$ rigid PU-clay nanocomposite foams made from polyether polyol. They found that the compressive modulus increased and the mean cell size decreased with addition of clay. Liang and Shi [19] researched the property of compressive strength of high-density (170$220 \mathrm{~kg} / \mathrm{m}^{3}$ ) soy-polyol-based PU foams incorporated by modified nanoparticles, Cloisite $30 \mathrm{~B}$. They reported that the density increased as the nanoclay loading increased, due to a higher density of nanoclay than the PU foam and a higher viscosity of the nanoclay polyol mixture than the polyol. The compressive strength and modulus increased first and then decreased as the nanoclay loading increased. The increase in the compressive strength and modulus of nanoclay soybased PU foams resulted from the higher-density and smaller cell size. But at high nanoclay loading, it was difficult to uniformly disperse the nanoparticles into the polyol mixture and this caused less uniform and some larger cell size, so the compressive strength and modulus decreased. The effect of microsphere and nanoclay on the properties of low-density $\left(45-50 \mathrm{~kg} / \mathrm{m}^{3}\right)$ soybean oil-based rigid polyurethane foams has not been reported in the literature. The objective of this study was to investigate the properties of low-density soybean oil-based rigid polyurethane foams modified by different loadings of glass microspheres and nanoclay.

\section{Materials and Methods}

2.1. Materials. The isocyanate, PAPI 27, used in this study was a polymeric diphenylmethane diisocyanate (MDI), with functionality 2.7 and isocyanate equivalent weight 134 . The petroleum-based polyol, VORANOL 490, is a polyether polyol, with hydroxyl number 490 and equivalent weight 114.5. Both PAPI 27 and VORANOL 490 were obtained from Dow Chemical Company (Midland, MI). Soybean oilbased polyol, with hydroxyl number 250 and equivalent weight 224.4, was made from fully epoxidized soybean oil by alcoholysis reaction using p-toluenesulfonic acid as catalyst to promote the oxirane ring opening reaction [20].

Dimethylcyclohexylamine and pentamethyldiethylenetriamine were used as catalysts. The fillers used in this study were glass microspheres and nanoclay. The glass spheres were hollow, spherical nonporous beads and the nanoclay was hydrophilic bentonite without surface modification. The dimethylcyclohexylamine, pentamethyldiethylenetriamine, glass microspheres, and nanoclay were obtained from Sigma-Aldrich (St. Louis, MO). Dabco DC 5357 from Air Products \& Chemicals (Allentown, PA) was used as the surfactant and distilled water was used as the blowing agent.

2.2. Foaming Formulation and Foam Preparation. Based on the results from a preliminary experiment, when reinforced with $1 \%$ glass microspheres, rigid PU foams made from 30 and 50\% soybean oil-based polyol had remarkably inferior density-compressive strength property to the control foams made from 100\% VORANOL 490. Therefore, a lower percentage $(15 \%)$ of soybean oil-based polyol was used in the final foaming formulation. The PU foams modified with glass microspheres and nanoclay were prepared by oneshot and free-rising method, and the foaming formulation is shown in Table 1. Initially the glass microspheres (or nanoclay) were dispersed in the preweighed polyols in a plastic cup using an electric mixer operating at $3450 \mathrm{rpm}$ for $15 \mathrm{~s}$. Water, catalysts, and surfactant were then added and mixed for an additional $15 \mathrm{~s}$. This polyol mixture (Bside materials) was allowed to degas for $120 \mathrm{~s}$. Thereafter, PAPI 27 (A-side material) was rapidly added to the cup and mixed at the same speed for another $10 \mathrm{~s}$ before dispensing into a wooden mold $(11.4 \times 11.4 \times 21.6 \mathrm{~cm})$ lined with aluminum foil to produce free-rise foams. All foams were cured at ambient temperature $\left(23^{\circ} \mathrm{C}\right)$ for $24-48 \mathrm{~h}$ before thermal conductivity measurement and 7 days for other tests. 
TABLE 1: Foaming formulation of rigid soybean oil-based polyurethane foams (SBO PU foams) modified with fillers.

\begin{tabular}{|c|c|c|}
\hline \multirow{2}{*}{$\begin{array}{l}\text { Ingredients } \\
\text { B-side materials }\end{array}$} & \multicolumn{2}{|c|}{ Concentration, $\mathrm{php}^{\mathrm{a}}$} \\
\hline & $\begin{array}{l}\text { Control PU } \\
\text { foams }\end{array}$ & SBO PU foams \\
\hline $\begin{array}{l}\text { VORANOL } 490 \\
\text { (Petroleum-based polyol) }\end{array}$ & 100 & 85 \\
\hline Soybean oil-based polyol & 0 & 15 \\
\hline $\begin{array}{l}\text { Dimethylcyclohexylamine } \\
\text { (gelling catalyst) }\end{array}$ & 0.84 & 0.84 \\
\hline $\begin{array}{l}\text { Pentamethyldiethylenetriamine } \\
\text { (blowing catalyst) }\end{array}$ & 1.26 & 1.26 \\
\hline Dabco DC 5357 (surfactant) & 2.5 & 2.5 \\
\hline $\begin{array}{l}\text { Distilled Water } \\
\text { (blowing agent) }\end{array}$ & 3.0 & 3.0 \\
\hline $\begin{array}{l}\text { Filler } \\
\text { (glass microsphere or nanoclay) }\end{array}$ & 0 & $1,3,5,7$ \\
\hline \multicolumn{3}{|l|}{ A-side material } \\
\hline Isocyanate index ${ }^{\mathrm{b}}$ of PAPI 27 & 110 & 110 \\
\hline $\begin{array}{l}\text { a The concentration of all ingredients a } \\
\text { of polyol, which conventionally dictat } \\
\text { to } 100 \text { parts. } \\
\text { b The amount of isocyanate used } r \\
\text { amount. The isocyanate index is the ra } \\
\text { used over theoretical amount of isocy }\end{array}$ & $\begin{array}{l}\text { expressed in pa } \\
\text { that the sum o } \\
\text { tive to the th }\end{array}$ & $\begin{array}{l}\text { s per hundred part } \\
\text { all polyols adds up } \\
\text { rretical equivalent } \\
\text { ount of isocyanate } \\
\text { s } 100 \text {. }\end{array}$ \\
\hline
\end{tabular}

2.3. Foam Property Measurement. The optical density of B-side materials with varied filler percentages was tested by GENESYS 20 spectrophotometer (thermo spectronic, Rochester, NY) at a wavelength of $600 \mathrm{~nm}$. The apparent density of the foam samples was measured according to American Society of Testing Materials (ASTM) D1622-08 [21]. The compressive strength was tested according to ASTM C1621-10 [22] by a TA.HDi Texture Analyzer with XTRA Dimension software (Texture Technologies Corp., Scarsdale, NY). In both density and compressive strength, the size of the specimen was $6.35 \times 6.35 \times 3.81 \mathrm{~cm}$. Five specimens were used for each treatment and the average was reported. The apparent thermal conductivity was determined according to ASTM C518-10 [23] using a Fox 200 heat flow meter instrument (LaserComp, Wakefield, MA). Two specimens were used for each treatment and the size of specimen was $20 \times 20 \times 2.5 \mathrm{~cm}$. The surface foaming temperature was monitored and recorded by an Omega Engineering OS 552A-MA-4 infrared thermometer equipped with a wireless transmitter and receiver (Omega Engineering Inc., Stamford, CT). The infrared thermometer was fixed at $40.64 \mathrm{~cm}$ above the wooden mold and focused on the center of the mold, an area of $2.54 \mathrm{~cm}$ in diameter. The response time of the temperature recording was $1 \mathrm{~s}$ [24]. The morphology of the foams was observed by a Hitachi S- 4700 field emission scanning electron microscope (FESEM, Tokyo, Japan). The sample was cut into $3 \mathrm{~mm}$ cubes and attached to the substrate with silver glue. After being coated with gold by a plasma sputter, the sample was moved into the chamber and micrographs were taken at an accelerating voltage of $5000 \mathrm{~V}$ and emission current of $9700 \mathrm{nA}$ [25].

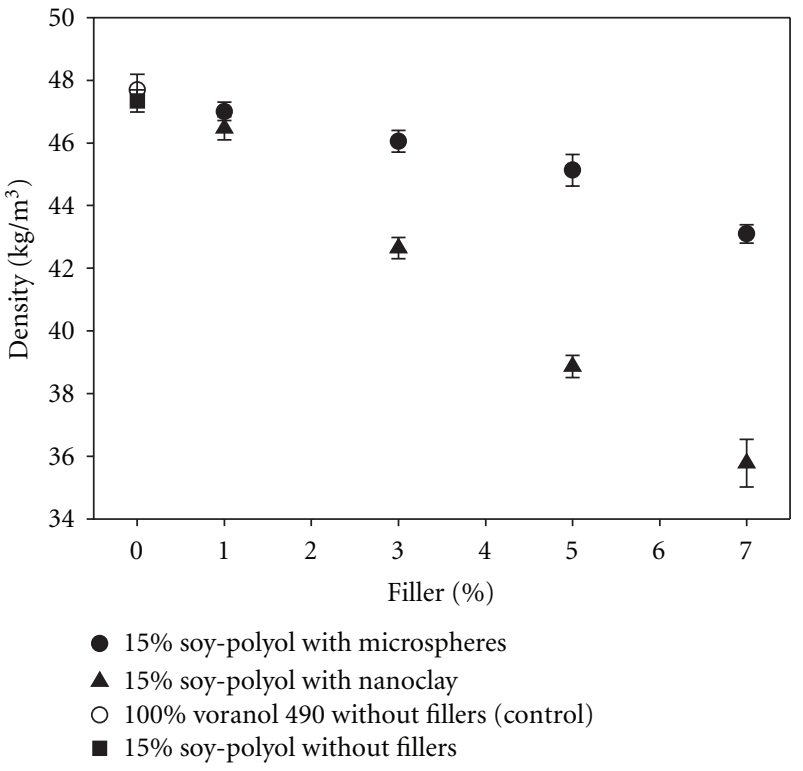

FIGURE 1: The effect of microspheres and nanoclay on density of SBO PUF.

\section{Results and Discussion}

3.1. Density. The effect of glass microspheres and nanoclay on density of soybean oil-based polyurethane foams (SBO PUF) is shown in Figure 1. SBO PUF without fillers showed a slightly lower density than the control foam. This was because while their volumes were similar due to using the same amount of blowing agent, SBO PUF had less weight than the control foam due to the fact that soybean oil-based polyols had a lower hydroxyl number than VORANOL 490 thereby using less isocyanate in the formulation. Increase in foam density after the addition of fillers has been reported in the literature $[12,13,19]$. In this study, however, when increasing the filler concentration from 1 to $7 \%$, the density of SBO PUF with microspheres decreased from 47 to $43 \mathrm{~kg} / \mathrm{m}^{3}$ while the density of SBO PUF with nanoclay decreased from 46.5 to $35.5 \mathrm{~kg} / \mathrm{m}^{3}$. Both the polyol-isocyanate and water-isocyanate reactions were exothermic. During the foaming process, carbon dioxide was generated from the reaction of water and isocyanate. Due to the release of heat from the exothermic reactions, the carbon dioxide bubbles grew and expanded the polymerizing polymer to form a foam volume [26]. In control foams, rapid mixing of the polyol mixture and isocyanate brought many microbubbles of air into the liquid system, which served as sites for bubble growth. When dispersing microspheres or nanoclay into the liquid mixture, their presence offered more nucleation sites for gas bubble formation. The increase of foam volume with increase of filler concentration was also visually observed in the experiments. On the other hand, the dispersibility of glass microspheres and nanoclay in the polyol mixture is different. Table 2 shows that, at the same filler percentage, the optical density $\left(\mathrm{OD}_{600}\right)$ of polyol with nanoclay, which is more hydrophilic, was always higher than that of polyol with glass microspheres. These results revealed 
TABLE 2: Changes in optical density (OD) at $600 \mathrm{~nm}$ for B-side materials containing various filler percentages.

\begin{tabular}{lccccc}
\hline Filler percentage (\%) & 0 & 1 & 3 & 5 & 7 \\
Glass microspheres & 0 & 0.439 & 0.795 & 1.236 & 1.668 \\
Nanoclay & 0 & 0.882 & 1.511 & 2.047 & 2.557 \\
\hline
\end{tabular}

that nanoclay had better dispersibility and was more easily dispersed in the polyol mixture than the glass microspheres. It appears nanoclay might have provided more nucleation sites than glass microspheres for bubble formation leading to a larger foam volume. Therefore the foam with nanoclay had a lower density that with glass microspheres.

3.2. Compressive Strength and Morphology. Figure 2 displays the effect of microspheres and nanoclay on compressive strength (CS) of SBO PUF. The mechanical properties of PUF are influenced by several parameters such as density, crosslinking density, and cell geometry [27-31]. In general, foams with higher density and/or cross-linking density are expected to be more rigid as well as higher in CS. The CS of SBO PUF without fillers was lower than that of the control. This was because soybean oil-based polyol had a lower hydroxyl number to react with isocyanate and thus SBO PUF had a lower cross-linking density than control made from VORANOL 490 [24, 28]. In SBO PUF with microspheres, the CS slightly decreased when increasing this filler concentration from 0 to $3 \%$ and then gradually increased. At $7 \%$ microsphere concentration, it was encouraging that CS of SBO PUF was similar to the control. In SBO PUF with nanoclay, CS remained at the same level around $380 \mathrm{kPa}$ when increasing the filler concentration from 1 to $5 \%$, but then decreased to $310 \mathrm{kPa}$ at $7 \%$.

Figures 3 and 4 show the scanning electron micrographs (SEM) of SBO PUF modified with glass microspheres and nanoclay, respectively. As shown, SBO PUF without fillers had a large number of cells in the shape of irregular polyhedra. When fillers were introduced and with increasing filler concentration, it could be visually observed that foam cell number increased and foam cell size decreased. During foaming process, the surface of the fillers provided many nucleation sites for bubble formation. Also, the addition of fillers increased the viscosity of the liquid system thus reducing coalescence among the bubbles [18]. Both effects were enhanced with increasing filler concentration leading to foams with more cells as well as smaller cell size.

Both cell size decrease and cell number increase contributed to a higher CS because more cell walls and struts per unit area of PU foams were present to support the foam structure under loading. Furthermore, incorporation of fillers in the cell walls and struts strengthened the hardness of the foams. On the other hand, the density of SBO PUF in Figure 1 decreased with increasing microsphere concentration, thereby decreasing CS to some extent. The overall CS of SBO PUF was dictated by the positive effects of fillers on polymer reinforcement and foam morphology and the negative effects of decreasing foam density $[17,19]$. Consequently, CS in SBO PUF with microsphere decreased

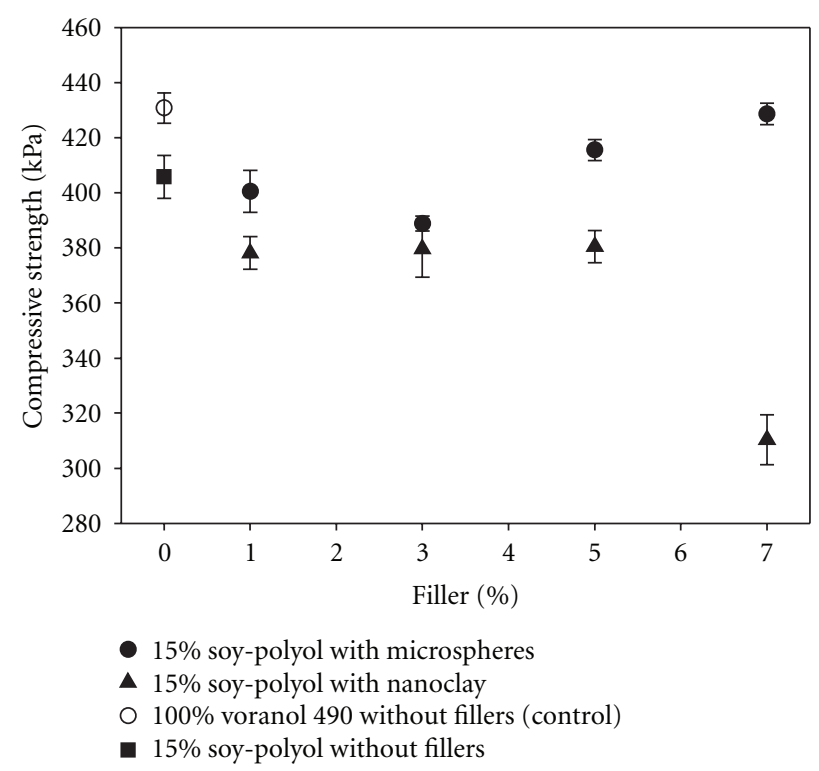

FIGURE 2: The effect of microspheres and nanoclay on compressive strength of SBO PUF.

slightly first (when the effect of foam density was more prominent) and then increased (when the effect of filler was more prominent). In SBO PUF with nanoclay, the CS remained at the same level from nanoclay concentration of 1 to $5 \%$ (when the effects of foam density and filler were similar), but significantly decreased at 7\%. This was because the large foam volume at $7 \%$ nanoclay concentration resulting in a sharp decrease in foam density and cross-linking density, which in turn diminished the CS.

3.3. Density-Compressive Strength. The density-compressive strength property of SBO PUF reinforced with fillers using $3 \%$ water content as the blowing agent is shown in Figure 5. The open circle symbols represent the PUF made from $100 \%$ voranol 490 with water content ranging from 2 to $4 \%$. For rigid polyurethane foams with various levels of blowing agent, there is a linear relationship between density and compressive strength $[32,33]$. In Figure 5 , foams located on the left side of the regression line have inferior density-compressive strength property to the control (higher density foams at the same compressive strength or lower compressive strength foams at the same density) while foams on the right side of the regression line have superior density-compressive strength property. SBO PUF without fillers (the solid square symbol) was on the left side of the regression line, showing an inferior density-compressive strength property to the control foam. With the addition of fillers, it was interesting to note that some SBO PUF (those containing $5-7 \%$ glass microsphere or $3-7 \%$ nanoclay) displayed comparable or superior density-compressive strength property to the control foam.

3.4. Surface Temperature History during Foaming. The surface temperature history of SBO PUF modified with microspheres and nanoclay during foaming is shown in 


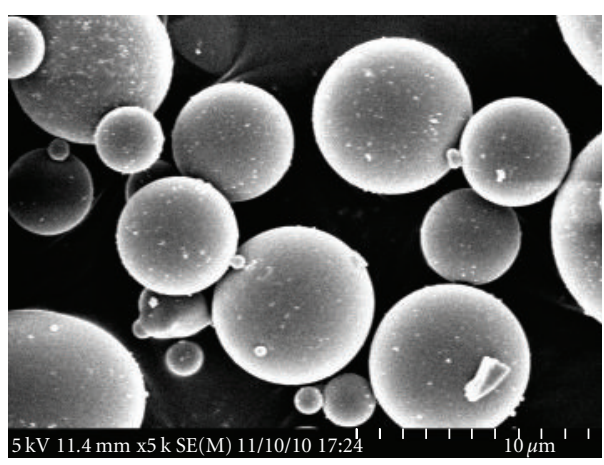

(a) Microspheres

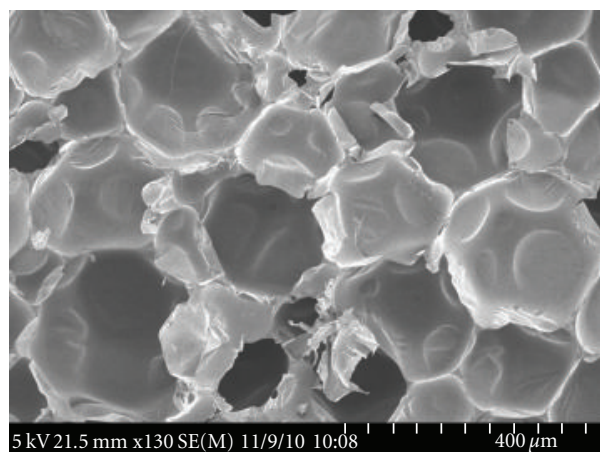

(c) SBO PU foam with $1 \%$ microspheres

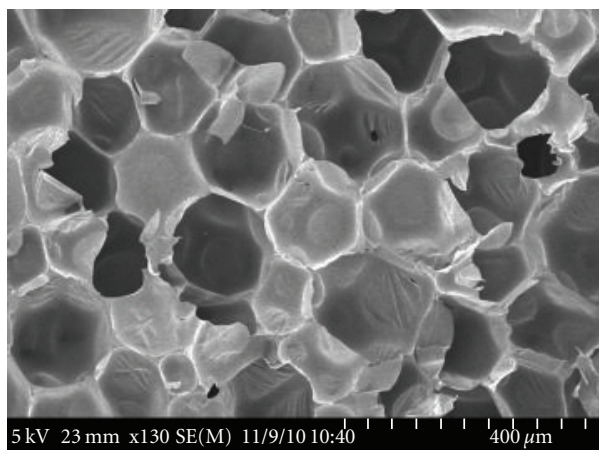

(e) SBO PU foam with 5\% microspheres

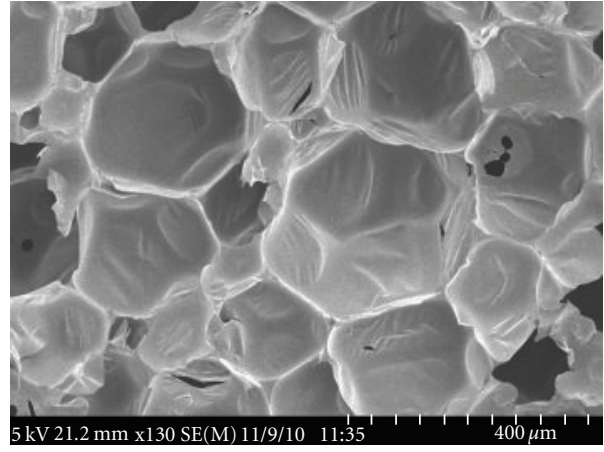

(b) SBO PU foam without fillers

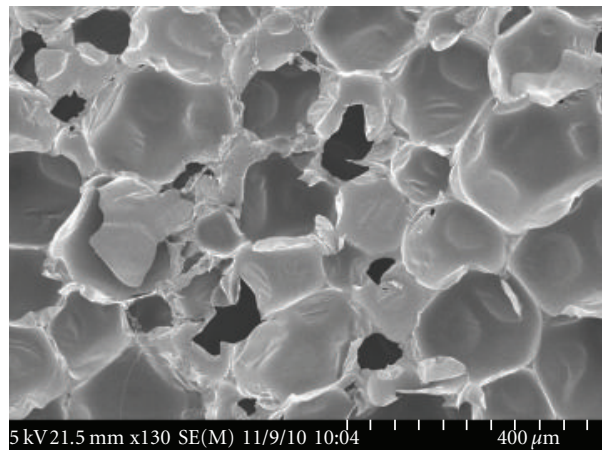

(d) SBO PU foam with 3\% microspheres

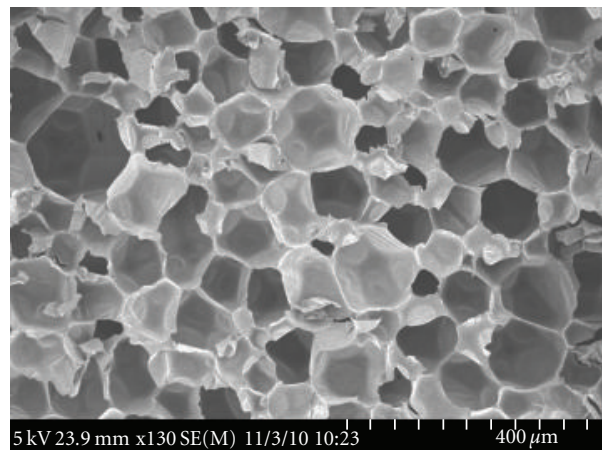

(f) SBO PU foam with $7 \%$ microspheres

FIgURE 3: Scanning electron micrographs of SBO PU foams modified with microspheres.

Figures 6 and 7, respectively. In general, the surface temperature rose sharply initially, reached its maximum, and then gradually dropped. This is expected because both polyolisocyanate and water-isocyanate reactions are exothermic. The maximal foam surface temperature of the control was slightly higher and remained higher afterward than that of SBO PUF. This was caused by the lower reactivity of SBOP with isocyanate than petroleum polyol. Derived from vegetable oils, SBOP had a branched triglyceride structure, and contained secondary hydroxyl groups, which were located in the middle of the triglyceride alkyl chains [20,34]. During polymerizing process, steric hindrance to cross-linking would occur because of the bulky aromatic isocyanate in SBO PUF while VORANOL 490 was linear in chemical structure and had primary hydroxyl groups [35]. The filler concentration did not seem to influence the surface temperature history of SBO PUF during foaming. This was not unexpected because the fillers were not involved in the exothermic reactions.

3.5. Thermal Conductivity. The effect of fillers on thermal conductivity and closed cell percentage of SBO PUF is shown in Figure 8. The thermal conductivity of plastic foams is the sum of thermal conductivities of the solid phase and the gas phase. Derived from vegetable oils, the hydroxyl groups in SBOP are secondary, while they are primary in voranol 490. Under the same condition, the secondary hydroxyl groups are three-times slower than the primary hydroxyl groups when they react with isocyanate functional groups $[25,33$, 35 . The lower reactivity of SBOP with isocyanate might have decreased the strength of the cell walls and therefore the cells had a lower capacity to entrap the carbon dioxide. Also, from 


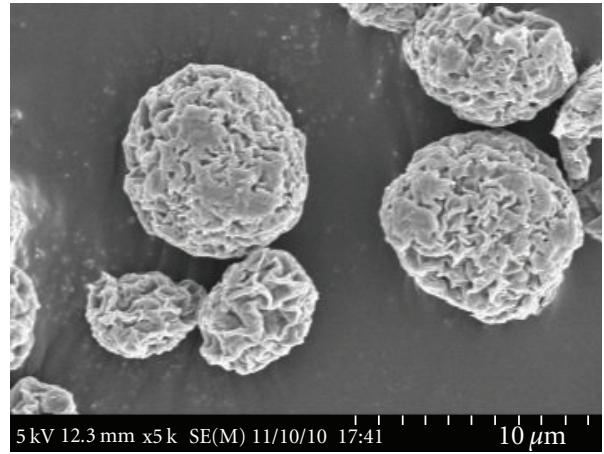

(a) Nanoclay

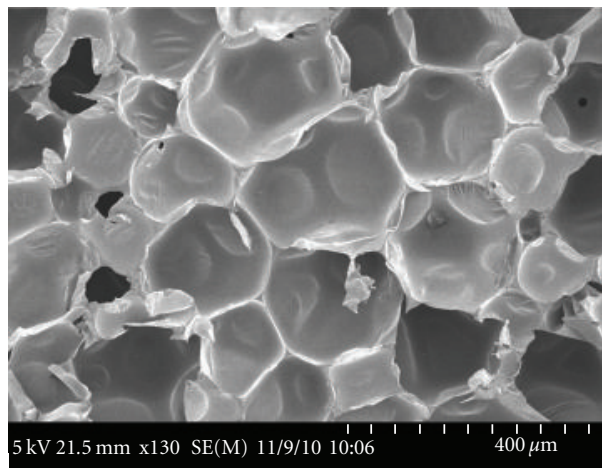

(c) SBO PU foam with $1 \%$ nanoclay

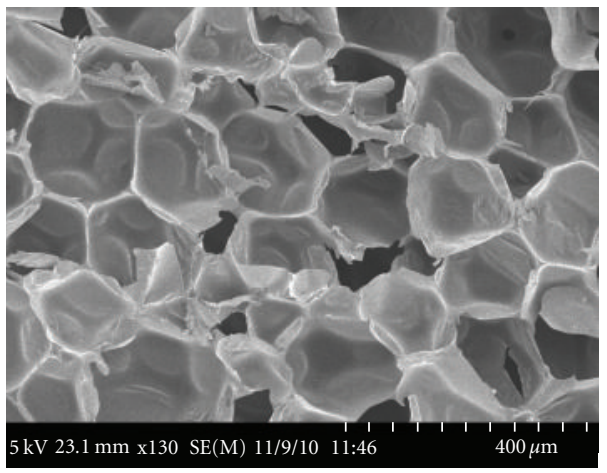

(e) SBO PU foam with $5 \%$ nanoclay

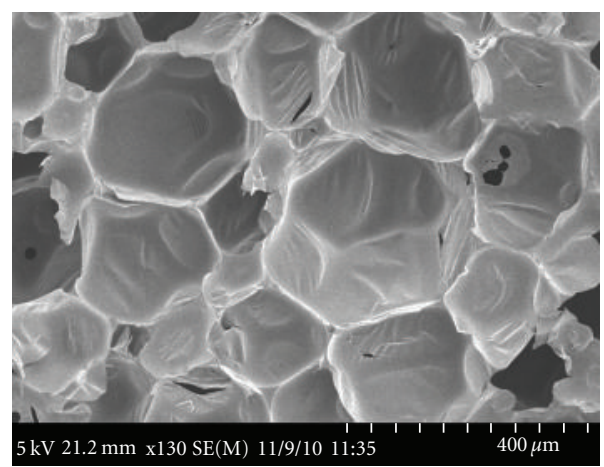

(b) SBO PU foam without fillers

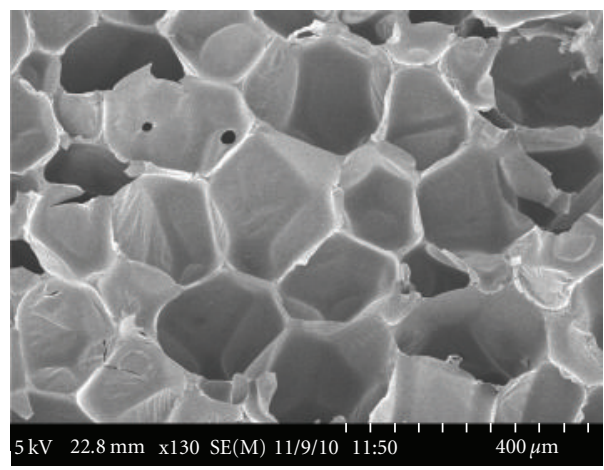

(d) SBO PU foam with 3\% nanoclay

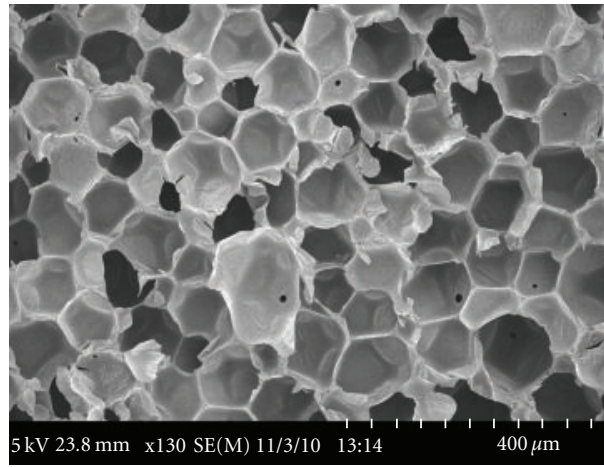

(f) SBO PU foam with 7\% nanoclay

FIGURE 4: Scanning electron micrographs of SBO PU foams modified with nanoclay.

Figure 1, it was known that the volume of SBO PUF increased with increasing filler concentration due to formation of more nucleated bubbles. In foams with a larger volume, their cell walls became thinner and weaker, and these cells burst more easily in foam rising phase. Thus the closed cell percentage of SBO PUF slightly decreased with increasing filler percentage (Figure 8), which in turn increased the thermal conductivity of the gas phase in plastic foams.

\section{Conclusion}

This work studied the physical properties of soybean oilbased rigid PU foams modified with glass microspheres and nanoclay in the concentration ranging from 1 to $7 \%$. Because the filler surface offered nucleation sites for bubble formation, the foam volume increased with increase of filler concentration. As filler concentration increased, the density decreased. When incorporated with microspheres, the compressive strength of SBO PUF decreased slightly from 1 to $3 \%$, and then increased up to $7 \%$. At $7 \%$ microsphere concentration, SBO PUF displayed the same compressive strength as the control. When incorporated with nanoclay, the compressive strength of SBO PUF generally remained at the same level from 1 to $5 \%$, and then decreased at $7 \%$ due to decrease in density and weaker cell walls and struts. Considering the property of density-compressive strength, the filler did reinforce the cell walls and improved the mechanical properties of SBO PUF. It was encouraging that some SBO 


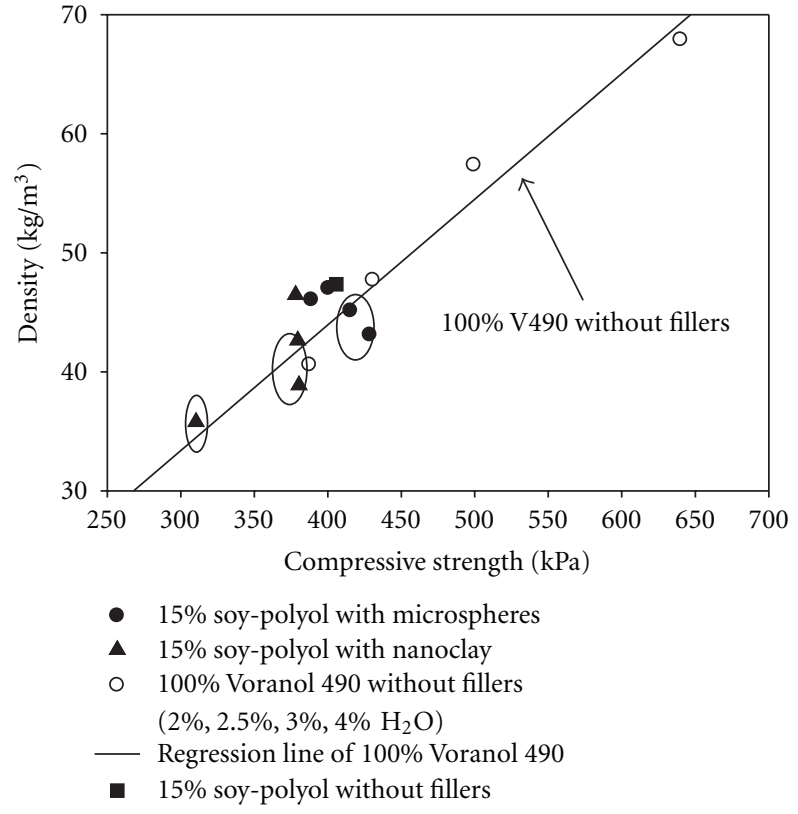

FIGURE 5: The effect of microspheres and nanoclay on densitycompressive strength of SBO PUF.

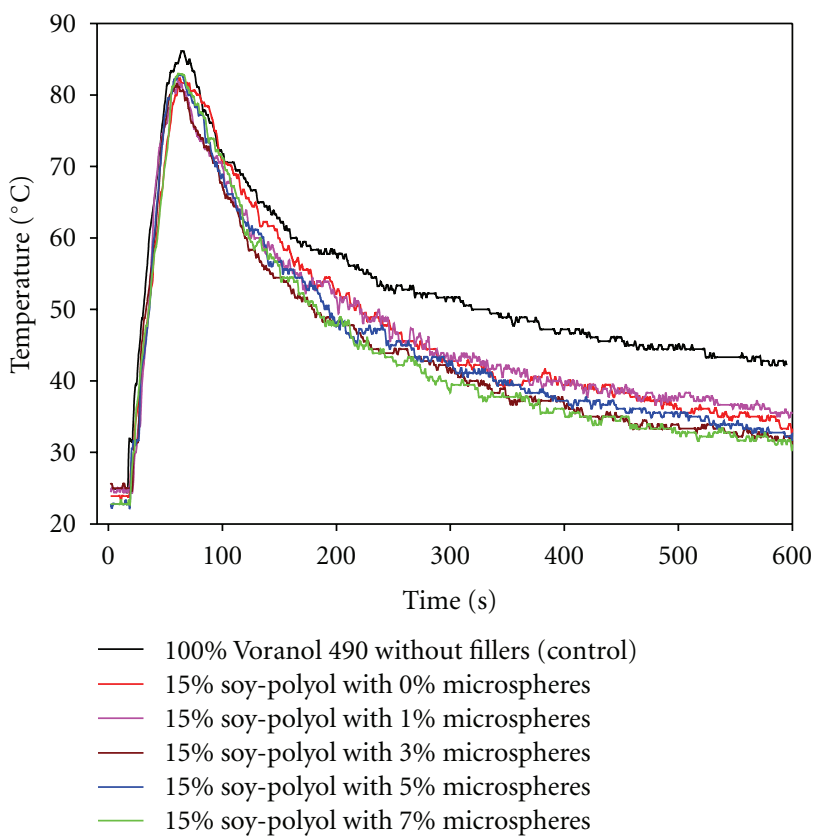

FIGURE 6: Foaming temperature of control and SBO PUF made from $15 \%$ soybean oil-based polyol and modified with microspheres.

PUF (containing 5-7\% microspheres or 3-7\% nanoclay) displayed comparable or superior density-compressive strength property to the control. Observation from SEM showed the increase of cell number and decrease of cell size in SBO PUF with addition of fillers. In the foaming temperature, the SBO PUF with the same filler basically remained the same during the foaming process. In addition, the presence

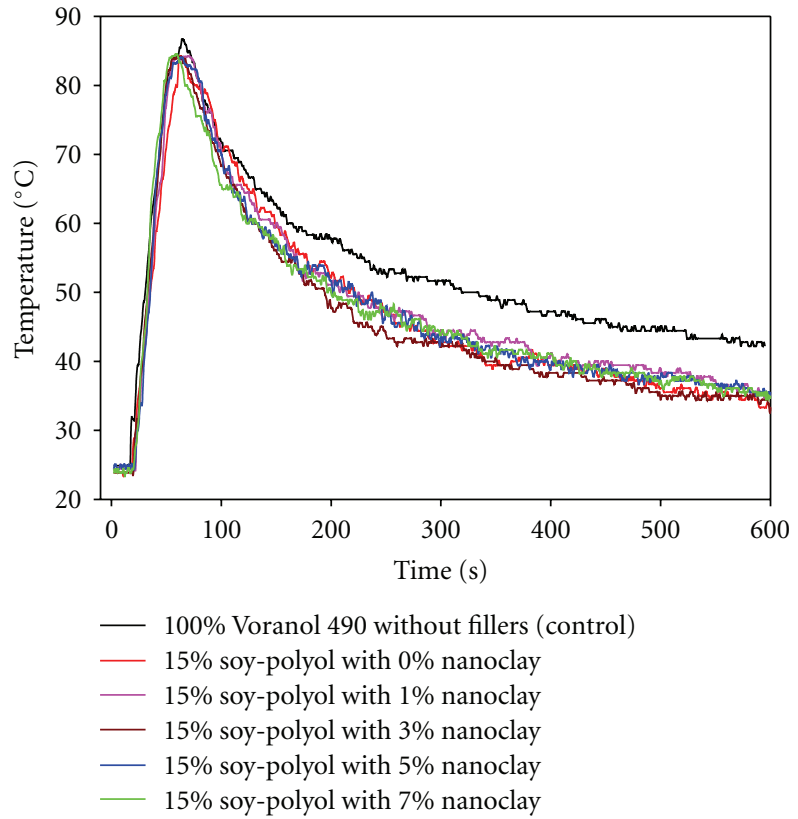

FIGURE 7: Foaming temperature of control and SBO PUF made from $15 \%$ soybean oil-based polyol and modified with nanoclay.

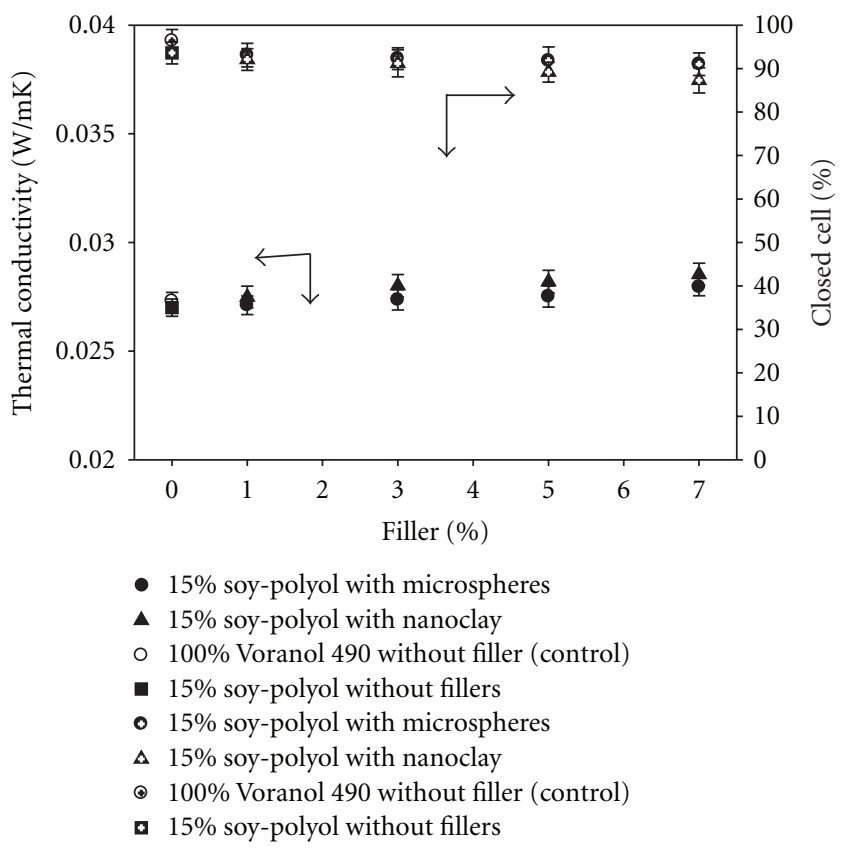

FIGURE 8: The effect of microspheres and nanoclay on thermal conductivity and closed cell percentage of SBO PUF.

of fillers increased slightly the thermal conductivity of SBO PUF.

\section{References}

[1] K. Ashida, Polyurethane and Related Foams: Chemistry and Technology, CRC/Taylor \& Francis, Boca Raton, Fla, USA, 2007. 
[2] J. Huffman, "Polyurethanes grow strongly in' 04 but face feedstock pressure," Chemical Market Reporter, vol. 266, no. 13, pp. 1-22, 2004.

[3] Chemical Week, "Construction to Drive PU Demand," 168 (17): 33, 2006.

[4] Economic Research Service, "Soybeans and Oil Crops: Market Outlook," USDA, 2010, http://www.ers.usda.gov/Briefing/ SoybeansOilcrops/2010_19baseline.htm.

[5] Economic Research Service, "Adoption of Genetically Engineered Crops in the U.S.," USDA, 2010, http://www.ers.usda .gov/Data/BiotechCrops/.

[6] A. Guo, D. Demydov, W. Zhang, and Z. S. Petrovic, "Polyols and polyurethanes from hydroformylation of soybean oil," Journal of Polymers and the Environment, vol. 10, no. 1-2, pp. 49-52, 2002.

[7] I. Banik and M. M. Sain, "Water blown soy polyol-based polyurethane foams of different rigidities," Journal of Reinforced Plastics and Composites, vol. 27, no. 4, pp. 357-373, 2008.

[8] S. S. Narine, X. Kong, L. Bouzidi, and P. Sporns, "Physical properties of polyurethanes produced from polyols from seed oils: II. Foams," Journal of the American Oil Chemists' Society, vol. 84, no. 1, pp. 65-72, 2007.

[9] R. Wool and X. Sun, Bio-Based Polymers and Composites, Elsevier Academic Press, Burlington, Mass, USA, 2005.

[10] I. Javni, W. Zhang, and Z. S. Petrović, "Effect of different isocyanates on the properties of soy-based polyurethanes," Journal of Applied Polymer Science, vol. 88, no. 13, pp. 2912-2916, 2003.

[11] T. W. Pechar, G. L. Wilkes, B. Zhou, and N. Luo, "Characterization of soy-based polyurethane networks prepared with different diisocyanates and their blends with petroleum-based polyols," Journal of Applied Polymer Science, vol. 106, no. 4, pp. 2350-2362, 2007.

[12] L. C. Chang, Y. Xue, and F. H. Hsieh, "Dynamic-mechanical study of water-blown rigid polyurethane foams with and without soy flour," Journal of Applied Polymer Science, vol. 81, no. 8, pp. 2027-2035, 2001.

[13] Y. Lin and F. Hsieh, "Water-blown flexible polyurethane foam extended with biomass materials," Journal of Applied Polymer Science, vol. 65, no. 4, pp. 695-703, 1997.

[14] I. Banik and M. M. Sain, "Water-blown soy polyol based polyurethane foams modified by cellulosic materials obtained from different sources," Journal of Applied Polymer Science, vol. 112, no. 4, pp. 1974-1987, 2009.

[15] Wikipedia, 2010, http://en.wikipedia.org/wiki/ Nanotechnology.

[16] T. Widya and C. W. Macosko, "Nanoclay-modified rigid polyurethane foam," Journal of Macromolecular Science, vol. 44, no. 6, pp. 897-908, 2005.

[17] X. Cao, L. James Lee, T. Widya, and C. Macosko, "Polyurethane/clay nanocomposites foams: processing, structure and properties," Polymer, vol. 46, no. 3, pp. 775-783, 2005.

[18] P. Mondal and D. V. Khakhar, "Rigid polyurethane-clay nanocomposite foams: preparation and properties," Journal of Applied Polymer Science, vol. 103, no. 5, pp. 2802-2809, 2007.

[19] K. Liang and S. Q. Shi, "Nanoclay filled soy-based polyurethane foam," Journal of Applied Polymer Science, vol. 119, no. 3, pp. 1857-1863, 2011.

[20] Z. Lozada, Chemical modifications to produce soy-based polyols, Ph.D. dissertation, University of Missouri-Columbia, 2009.

[21] ASTM D1622-08, "Standard Test Method for Apparent Density of Rigid Cellular Plastics," 2008.

[22] ASTM D1621-10, "Standard Test Method for Compressive Properties of Rigid Cellular Plastics," 2010.
[23] ASTM C518-10, "Standard Test Method for Steady-State Thermal Transmission Properties by Means of the Heat Flow Meter Apparatus," 2010.

[24] Y. C. Tu, H. Fan, G. J. Suppes, and F. H. Hsieh, "Physical properties of water-blown rigid polyurethane foams containing epoxidized soybean oil in different isocyanate indices," Journal of Applied Polymer Science, vol. 114, no. 5, pp. 2577-2583, 2009.

[25] Y. C. Tu, G. J. Suppes, and F. H. Hsieh, "Water-blown rigid and flexible polyurethane foams containing epoxidized soybean oil triglycerides," Journal of Applied Polymer Science, vol. 109, no. 1, pp. 537-544, 2008.

[26] G. Woods, The ICI Polyurethane Book, John Wiley \& Sons, New York, NY, USA, 1990.

[27] M. Thirumal, D. Khastgir, N. K. Singha, B. S. Manjunath, and Y. P. Naik, "Effect of foam density on the properties of water blown rigid polyurethane foam," Journal of Applied Polymer Science, vol. 108, no. 3, pp. 1810-1817, 2008.

[28] H. Lim, S. H. Kim, and B. K. Kim, "Effects of the hydroxyl value of polyol in rigid polyurethane foams," Polymers for Advanced Technologies, vol. 19, no. 12, pp. 1729-1734, 2008.

[29] G. F. Smits, "Effect of cellsize reduction on polyurethane foam physical properties," Journal of Thermal Insulation and Building Envelopes, vol. 17, pp. 309-330, 1994.

[30] D. Klempner and V. Sendijarevic, Handbook of Polymeric Foams and Foam Technology, Hanser Gardener Publications, Cincinnati, Ohio, USA, 2004.

[31] M. Szycher, Szycher's Handbook of Polyurethanes, CRC Press, Boca Raton, Fla, USA, 1999.

[32] G. Oertel and L. Abele, Polyurethane Handbook: Chemistry, Raw Materials, Processing, Application, Properties, Hanser, New York, NY, USA, 1994.

[33] Y. C. Tu, P. Kiatsimkul, G. Suppes, and F. H. Hsieh, "Physical properties of water-blown rigid polyurethane foams from vegetable oil-based polyols," Journal of Applied Polymer Science, vol. 105, no. 2, pp. 453-459, 2007.

[34] Z. Lozada, G. J. Suppes, F. H. Hsieh, A. Lubguban, and Y. C. $\mathrm{Tu}$, "Preparation of polymerized soybean oil and soy-based polyols," Journal of Applied Polymer Science, vol. 112, no. 4, pp. 2127-2135, 2009.

[35] R. Herrington and K. Hock, Dow Polyurethane Flexible Foams, The Dow Chemical Company, Midland, Mich, USA, 1997. 

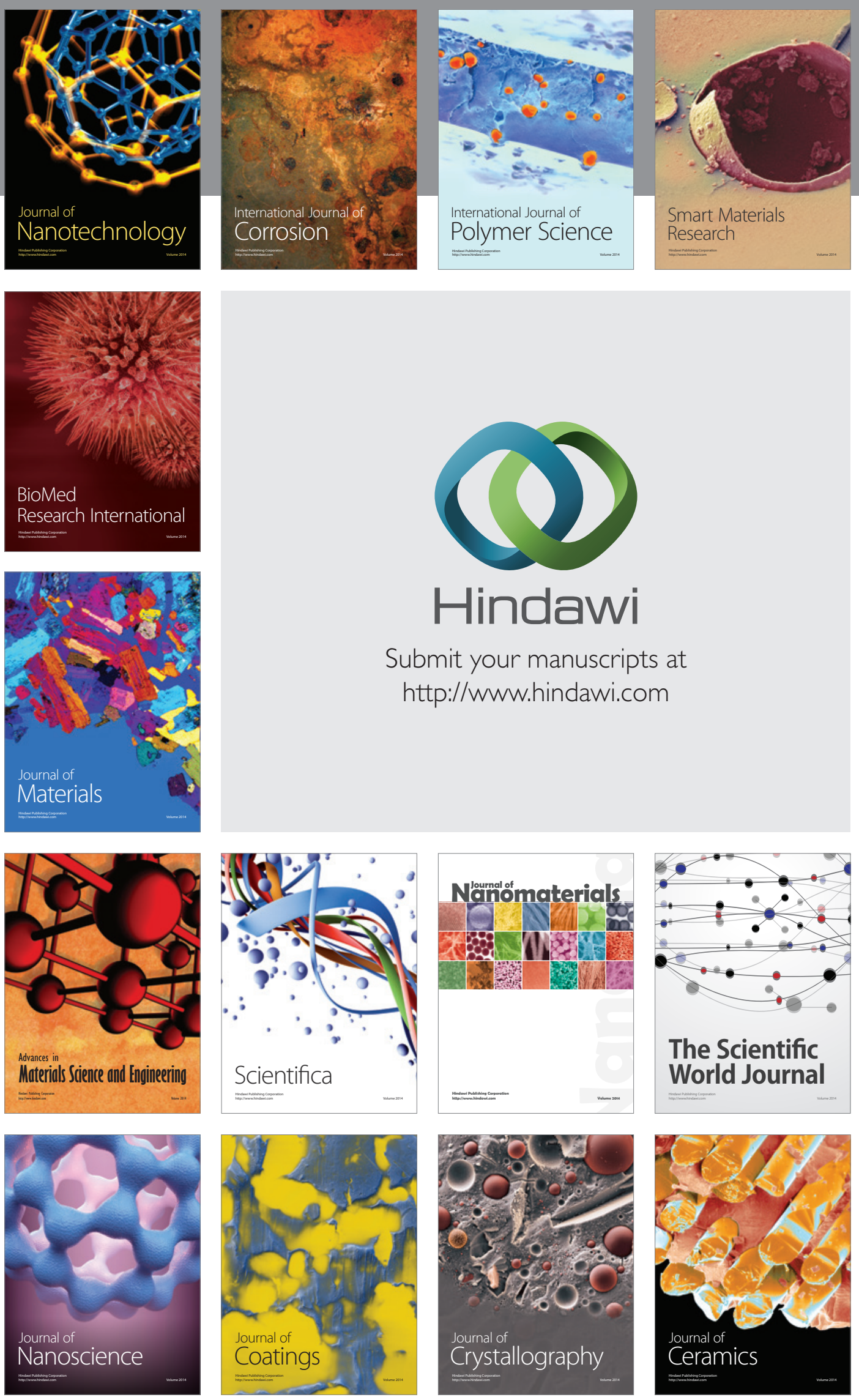

The Scientific World Journal

Submit your manuscripts at

http://www.hindawi.com

\section{World Journal}

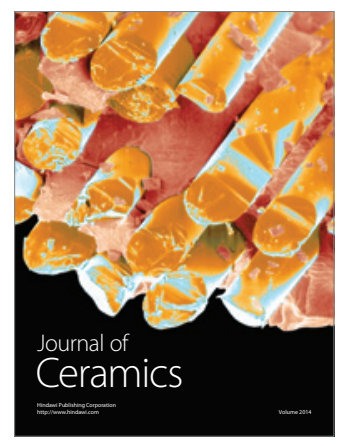

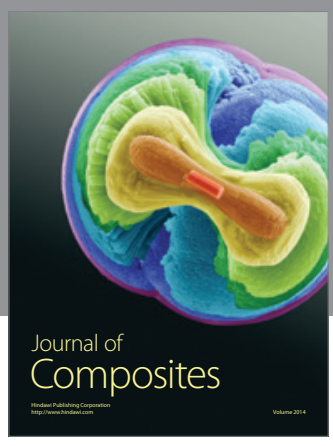
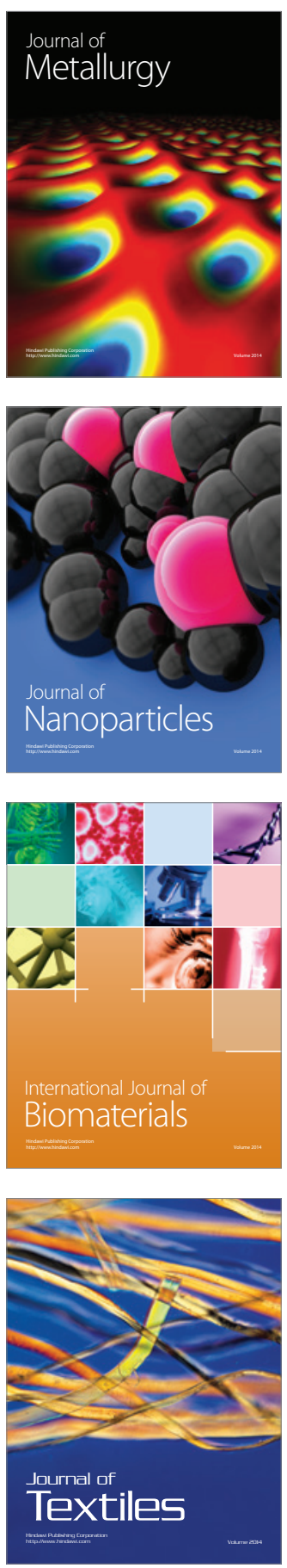